\title{
Non-Small Cell Lung Cancer Metastasis in Nasal Fossa: A Case Report and Literature Review
}

\author{
*Chaker ZAIDI, S Kanoun Belajouza and N Bouaouina \\ Department of radiation oncology, Farhat Hached Hospital, Tunisia \\ Submission:January 10, 2017; Published: January 24, 2017 \\ "Corresponding author: Zaidi Chaker, Department of radiation oncology, Farhat Hached Hospital, Medical school of Susah, Tunisia, \\ Tel: +216 55635100; Email: chakerblender@hotmail.fr
}

Abstract

Introduction: Metastases from below the clavicles, to the head and neck region, are relatively uncommon. Tumors in nasal cavity and para nasal sinuses are rare and metastases in this location are far less common. Non-small cell lung cancer (NSCLC) has been well known to metastasize to various unusual sites in the body and the bizarre behavior of NSCLC metastatic disease is documented. We report a case of NSCLC metastasis in nasal fossa. Case report a 54-year old, previously healthy man, heavy smoker, presented with cough and poor general condition. Chest CT scan showed an heterogeneous and calcified right pulmonary tumor with multiple enlarged hilar and meditational lymph nodes, and contlolateral pulmonary nodules (Figure 1).

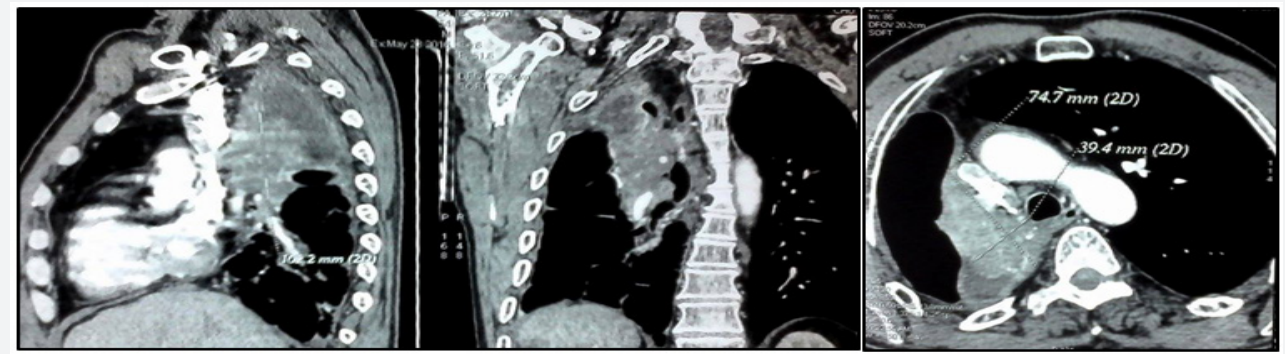

Figure 1: Contrast enhanced CT scan of the chest showing the lung tumor after chemotherapy: (A) sagittal view, (B) coronal view and $(\mathrm{C})$ axial view.

Histopathological findings: Revealed lung cancer non-small cells. Systemic metastatic work-up showed no more lesions and the patient underwent two regimen of palliative chemotherapy in the form of Gemzar and Cisplatin for 4 cycles followed by 4 cycles of Taxol Carboplatin with no radiological response, there were a mild increase of the size of the tumor. The patient tolerated well chemotherapy and another regimen of Navelbine was administered untill he presented recurrent nose bleed and gradually increasing fungating nasal mass. Head and neck CT scan showed an ovoid heterogeneous well-limited tumor, originating from anterior nasal septum wall (Figure 2).

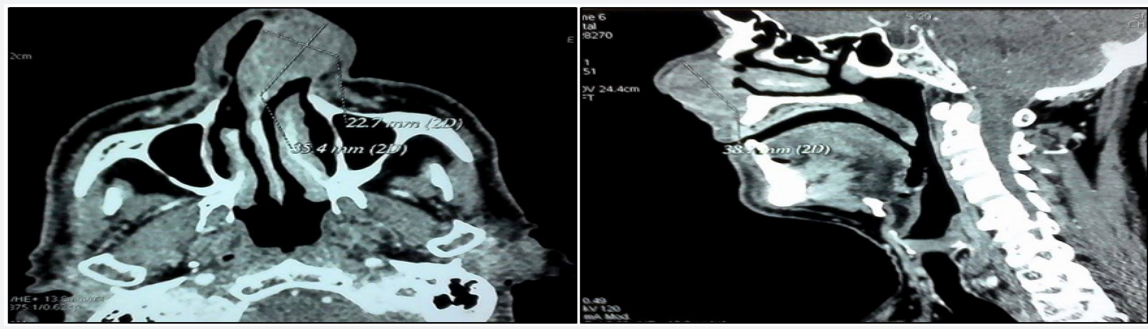

Figure 2: Contrast enhanced $C T$ of the head and neck before radiotherapy showing the nasal tumor invasing the nasal fossa and involving oral cavity: (A) axial view and (B) sagittal view.

Histopathological examination of the resected tumor specimen revealed NSCLC metastasis in nasal fossa. Multidisciplinary discussion indicated palliative hemostatic radiotherapy on the metastasis. The patient was irradiated at the dose of 30 Gy in 10 fractions. Two weeks later assessment showed mild decrease in tumor size and nasal bleeding. Conclusion: The prevalence of nasal fossa metastasis could be underestimated because of their resemblance to benign lesions and their late occurrence. The presenting symptoms for such tumors are similar to those who present with primary nasal fossa tumor, which makes diagnosis quite difficult, especially when they occur as an initial presentation of the tumor. Prognosis is miserable and it is usually resistant to both chemotherapy and radiotherapy. 


\section{Cancer Therapy \& Oncology International Journal}

\section{Introduction}

Metastases from below the clavicles, to the head and neck region, are relatively uncommon [1]. Tumors in nasal cavity and para nasal sinuses are rare and metastases in this location are far less common [2]. Non-small cell lung cancer (NSCLC) has been well known to metastasize to various unusual sites in the body and the bizarre behavior of NSCLC metastatic disease is documented $[3,4]$. We report a case of NSCLC metastasis in nasal fossa.

\section{Methods}

\section{Case report}

A 54-year old, previously healthy man, heavy smoker, presented with cough and poor general condition. Chest CT scan showed a heterogeneous and calcified right pulmonary tumor localized in the posterior segment of the right superior lobe involving the homo-lateral pulmonary helium measuring $10 \mathrm{~cm}$. It showed also multiple enlarged hilar and meditational

lymph nodes, and contlolateral pulmonary nodules. Bronchial endoscopy was normal and cytology findings revealed lung cancer non-small cells. Systemic metastatic work-up showed no more lesions and the patient underwent two regimen of palliative chemotherapy in the form of Gemzar and Cisplatin for 4 cycles followed by 4 cycles of Taxol Carboplatin with no radiological response, there were a mild increase of the size of the tumor.

The patient tolerated well chemotherapy and another regimen of Navelbine was administered untill he presented recurrent nose bleed and gradually increasing fungating nasal mass. Head and neck CT scan showed an ovoid heterogeneous well-limited tumor, originating from anterior nasal septum wall, measuring $35 \mathrm{~mm}$, with no invasion of adjacent dermic fat.

The tumor fulfills entirely the left nasal fossa and puches on maxillary bone. Histopathological examination of the resected tumor specimen revealed malignant tumoral infiltration composed of atypical epithelial cells with irregular hyperchromatic nuclei and non visible nucleoli, abundant cytoplasm and no dyskeratinisation or cell to cell adhesion functional complex. This was reported as a NSCLC metastasis in nasal fossa. Multidisciplinary discussion indicated palliative hemostatic radiotherapy on the metastasis. The patient was irradiated at the dose of $30 \mathrm{~Gy}$ in 10 fractions. Two weeks later assessment showed mild decrease in tumor size and nasal bleeding.

\section{Discussion}

The majority of distant metastases to the head and neck region are localized within the lymph nodes [1]. Nasal cavity metastasis are unfrequent and occurs principally in adults in the forth to sixth decade [2]. They are renowned for a wide range of morphological and clinical presentations depending on its extension and it could be slow-growing and painless which may delay diagnosis [2]. Common symptoms include recurrent epistaxis, nasal obstruction and facial pain $[5,6]$. Malignity must be suspected if any of the following signs are present a fast evolution, a hemorrhagic tendency, mechanical disorders caused by the development of the tumor and an ulcerated and/ or necrotic aspect [7].

Patients with such symptoms should be carefully examined, especially if they have previously been treated because of a malignant disease. CT scan may provide some views about the malignant nature of the lesion, such as bone erosion and remodeling, hypervascularity or expansion of the sphenopalatine foramen. Magnetic resonance imaging (MRI) shows the true extent of the lesion and provides more information such as infiltration of the skull base and leptomeningeal metastases. Combined positron emission tomography/computed tomography (PET/CT) is useful for the detection of primary tumors, if not diagnosed, or other metastasis [7-9].

The diagnosis is usually suspected clinically and after radiological investigations and it is confirmed histopathologically after biopsy by comparing histological and immunohistochemical findings to those of the primary tumor. The pathogenesis of these metastases is poorly elucidated. Metastases are a complicated processes in which the tumor cells have to detach from the primary tumor, and then spread in the tissue, invade the lymphovascular system, survive the journey in the circulation, and settle down at the metastatic site.

The vertebral venous plexus has been postulated as a possible route for the hematogenous dissemination of cancer cells to the head and neck. This low-pressure plexus communicates with the pelvic veins, intercostals veins, vena cavae and the azygos system. The malignant cells travel upwards to the pterygoid plexus, cavernous sinus and finally the nasal and para nasal sinuses $[10,11]$. Another pathogenic mechanism of cervicofacial metastases would be, in the case of metastases of lung cancers, the direct bronchotracheal way [12-15].

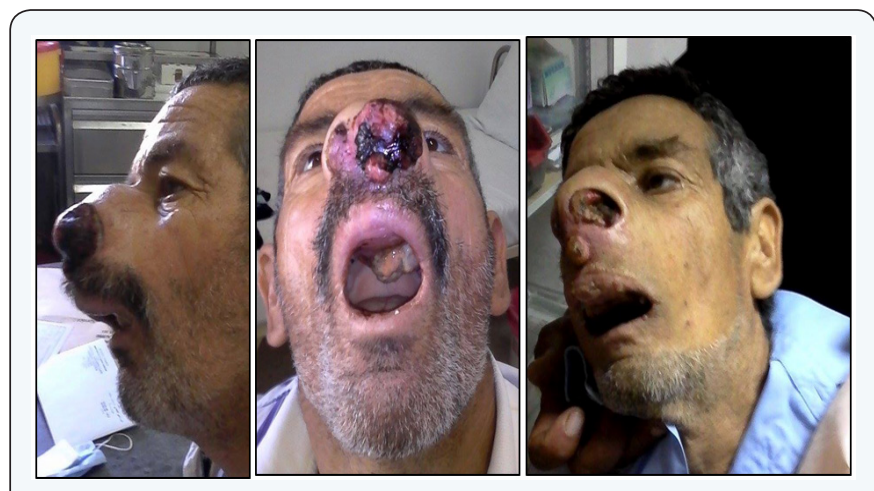

Figure 3: Patient pictures: $(A)$ and $(B)$ before radiotherapy of nasal metastasis, $(C)$ after radiotherapy.

Nasal fossa metastasis is usually a late occurrence and is most often associated with metastatic deposits in other organs. 
Prognosis is poor, it usually responds poorly to treatment and there are few available data demonstrating efficacy of palliative chemotherapy and radiotherapy in controlling these tumors $[1,7]$. Our case is interesting in view of the rare incidence of tumors in this location and even rarer metastasis from below clavicles. This report highlights the importance of suspecting metastases in this location especially in patients with a previous history of malignancy (Figure 3).

\section{Conclusion}

The prevalence of nasal fossa metastasis could be underestimated because of their resemblance to benign lesions and their late occurrence. The presenting symptoms for such tumors are similar to those who present with primary nasal fossa tumor, which makes diagnosis quite difficult, especially when they occur as an initial presentation of the tumor. Thus, biopsy is essential for establishment of the diagnosis. A complete survey of other organs is also important in determining the treatment. Prognosis is miserable and it is usually resistant to both chemotherapy and radiotherapy.

\section{References}

1. Bartłomiej K, Joanna KN, Stanisław B (2008) Distant metastases to nasal cavities and paranasal sinuses, from the organs outside the head and neck. Otolaryngol Pol 62(4): 422-425.

2. Weber AL, Strnton AC (1984) Malignant tumors of the paranasal sinuses: radiologic, clinical, and histopathologic evaluation of 200 cases. Head Neck Surg 6(3): 761-776.

3. Dooldeniya MD, Biyani CS, Weston PM (2009) An unusual presentation of non-small cell lung carcinoma. BMJ Case Rep.
4. Diem S, Früh M, Rodriguez R, Liechti P, Rothermundt C (2013) EML4ALK-positive pulmonary adenocarcinoma with anunusual metastatic pattern: a case report. Case Rep Oncol 6(2): 316-319.

5. Nelson EG, Goldman ME, Hemmati M (1990) Metastatic carcinoma of the ethmoid sinus. Otolaryngol Head Neck Surg 103(1): 120-123.

6. Lopez JI, Nevado M, Eizaguirre B, Perez A (1990) Intestinal-type adenocarcinoma of the nasal cavity and paranasal sinuses. A clinicopathologic study of 6 cases. Tumori 76(3): 250-254.

7. Azarpira N, Ashraf MJ, Khademi B, Asadi N (2011) Distant Metastases to Nasal Cavities and Paranasal Sinuses Case Series. Indian J Otolaryngol Head Neck Surg Oct 63(4): 349-352.

8. Kwee TC, Basu S, Alavi A (2011) PET and PET/CT for unknown primary tumors. Methods Mol Biol 727: 317-333.

9. Keller F, Psychogios G, Linke R, Lell M, Kuwert T, et al. (2011) Carcinoma of unknown primary in the head and neck: comparison between positron emission tomography (PET) and PET/CT. Head Neck 33(11): 1569-1575.

10. Bernstein JM, Montgomery WW, Balogh K (1966) Metastatic tumors to the maxilla, nose and paranasal sinuses. Laryngoscope 76(4): 621650 .

11. Lee HM, Kang HJ, Lee SH (2005) Metastatic renal cell carcinoma presenting as epistaxis. Eur Arch Otorhinolaryngol 262(1): 69-71.

12. Kufe DW, Holland JF, Pollock RE (2006) Cancer medicine - $7^{\text {th }}$ edition. Hamilton, Ontario: BC Decker.

13. Mareel M, Leroy A (2003) Clinical, cellular, and molecular aspects of cancer invasion. Physiol Rev 83(2): 337-376.

14. Hentati D, Chraiet N, Kochbati L, Maalej M (2007) Un carcinome pulmonaire métastase à la gencive via une aiguille de couture : à propos d'un cas. Cancer Radiother 11(8): 500-502.

15. Nicholas Zachariades (1989) Neoplasms Metastatic to the Mouth, Jaws and Surrounding Tissues. j CranioMaxFac Surg 17(6): 283-290.

This work is licensed under Creative Commons Attribution 4.0 License

DOI: 10.19080/CTOIJ.2017.03.555602

\section{Your next submission with Juniper Publishers will reach you the below assets}

- Quality Editorial service

- Swift Peer Review

- Reprints availability

- E-prints Service

- Manuscript Podcast for convenient understanding

- Global attainment for your research

- Manuscript accessibility in different formats ( Pdf, E-pub, Full Text, Audio)

- Unceasing customer service

Track the below URL for one-step submission https://juniperpublishers.com/online-submission.php 